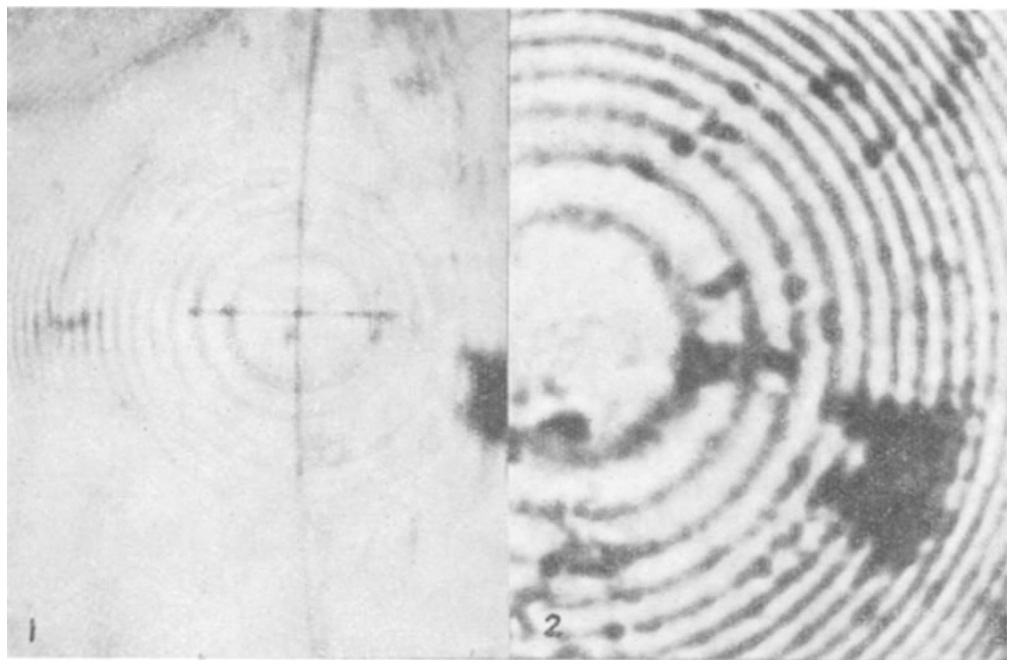

This method of determining the thermionic constants, and in particular the coefficient $A$ in Richardson's equation, has advantages over the other methods, since it is insensitive to the usual type of contamination of the emitting surface ; and further, it does not require a knowledge of the effective area of the emitting surface or of the reflexion coefficient of the electrons at the surface.

The inner walls of the graphite chamber, as also the regions close to the effusion hole, can be coated suitably with other metals, and the method can thus be used for the determination of the thermionic constants of these metals also. We have determined in this manner the thermionic constants of chromium, iron, cobalt and nickel, depositing

hence Newton's rings can be seen only faintly, superposed on the profile. The radius of curvature calculated from the interference fringes is $0.596 \mathrm{~mm}$. and from the profile $0.595 \mathrm{~mm}$., the estimated error in the latter being some \pm 1 per cent (that is, $\pm 0.005 \mathrm{~mm}$.).

There is, then, complete confirmation of the reliability of the light-profile method, particularly for measuring curvature of small bodies or small cavities. Spherical cavities, such as those produced in microindentation by spheres or ball-ended diamonds, erosion pits, cavities produced by spark discharges on metals, etc., are but some of the features now under examination.

S. TOLANSKY

Royal Holloway College

M. OMar

(University of London),

Englefield Green,

Surrey. July 16.

${ }_{1}^{1}$ Tolansky, S., Nature, 169, 445 (1952).

2 Tolansky, S., Zeitschrift für Elektrochemie, 56, 263 (1952).

${ }^{3}$ Omar, M., and Rahbek, H., Nature, 169, 1008 (1952).

- Tolansky, S., and Rahbek, H., Nature, 169, 1060 (1952).

\section{Thermionic Constants of the Iron Group of Metals}

IN a recent communication ${ }^{1}$, we gave an account of a new method of determining the thermionic constants of graphite, which is based on the determination of the saturation vapour pressure of the electron gas in equilibrium with the substance at different known temperatures, and application of the well-known thermodynamic relation of Clausius and Clapeyron. In the actual experiments, the saturation vapour pressure of the electron gas in a graphite chamber is determined by finding the rate of effusion of the gas into vacuum through a small hole in a thin wall of the chamber. The chamber is in the form of a thin-walled tube, and can be heated to any desired high temperature by sending a suitable heavy electric current through it. In order to eliminate the electrons emitted by the graphite surface adjoining the effusion hole, the surface is covered by a thin sheet of mica, with a small hole punctured in it ; this comes just in front of a bigger one in the graphite wall and serves as the effective effusion hole. the metals both electrolytically and by evaporation from a tungsten wire coated previously with the metal, or carrying small rings of the metal. The results were found to be independent of the method used for the deposition of the metal and were reproducible.

The observations fit well with Richardson's cquation :

$$
i=A T^{2} \exp (-\varphi / k T),
$$

in which $A$ and $\varphi$ are independent of temperature, and have the values given in the accompanying table.

\begin{tabular}{|c|c|c|}
\hline Metal & $\stackrel{\varphi}{\stackrel{e V}{V})}$ & (amp. $\mathrm{cm}^{-2}$ deg. ${ }^{-2}$ ) \\
\hline $\begin{array}{l}\text { Chromium } \\
\gamma \text {-Iron } \\
\text { Cobalt } \\
\text { Nickel }\end{array}$ & $\left.\begin{array}{l}4 \cdot 58 \\
4 \cdot 31 \\
4 \cdot 41 \\
4 \cdot 50\end{array}\right\} \pm 0 \cdot 02$ & $\left.\begin{array}{r}60 \\
60 \\
60\end{array}\right\} \pm 2$ \\
\hline $\begin{array}{l}\text { Note added } \\
\text { Titanium } \\
\text { Vanadium } \\
\text { Manganese }\end{array}$ & $\begin{array}{l}\text { ctober } 8 \text {. } \\
3.95 \\
4 \cdot 12 \\
3.83\end{array}$ & $\begin{array}{l}44 \\
50 \\
34\end{array}$ \\
\hline
\end{tabular}

As is well known, the observed fit of the experimental data with formula (1) with temperatureindependent constants $A$ and $\varphi$ cannot be regarded as excluding a small linear variation of the actual work function with temperature, since such a variation will be equivalent to a temperature-independent change in $A$. Apart from the normal thermal expansion of the metal, which will lead to a small temperature variation of the work function, there is a further source of such variation in these metals. The $d$ - and the $s$-energy bands of these metals overlap, the former being nearly full, and having a much larger density of energy-states than the latter. As a result, (1) the electronic specific heat in the condensed phase will be considerable, and (2) on change of temperature there will be a transference of electrons from one band to the other, and a consequent change in the work function ${ }^{2}$. Hence experimental data for the thermionic constants of the transition elements are of special interest.

K. S. KRISHNAN

S. C. JAIN

National Physical Laboratory of India, New Delhi. A.pril 15.

${ }^{1}$ Nature, 189, 702 (1952). See also Bhatnagar, A. S., Proc. Nat. Acad. Sci. India, A, 145 (1944). Mathur, S. B. L., doctorate thesis, University of Lucknow (1951). Krishnan, K. S., and Jain, S. C., Proc. Roy. Soc., A. (in the press).

2 TVohlfarth, E. P., Proc. Phys. Soc., 6), 360 (1948). 